\title{
Chronic venous insufficiency strengthens the thrombo-embolic risk in congestive heart failure in elderly patients
}

\author{
F Ciciarello ${ }^{*}$, S Mandolesi, D Mandolesi, G D’Ambrosio, F Fedele \\ From de Senectute: Age and Health Forum \\ Catanzaro, Italy. 5-7 December 2009
}

\section{Background}

As for other pathologies, the pathogenesis of venous thrombo-embolism (VTE) is multifactorial. A comprehensive understanding of the pathogenesis of venous thrombosis is essential for identifying patients at increased risk as in elderly patients with congestive heart failure (CHD) and with presence of chronic venous insufficiency (IVC). Eberhard Mammen postulated immobility as the leading event in the CHD, because it reduced blood flow as a result of decreased muscle contraction. The subsequent "stasis of flow" led to accumulation of blood within the intramuscular sinuses, especially of the calf, triggering hypercoagulability due to local accumulation of activated clotting factors and coagulation activation products and the simultaneous consumption of blood coagulation inhibitors.

\section{Materials and methods}

We have analyzed, in the latest years, the results of a comprehensive examination of 214 elderly (Group 1 ; aged $71+/ 12$ years) hospitalized with CHD and 187 patients (Group 2; aged 76+/-9 years) with CHD and venous disorders (CVI) in class $\mathrm{C} 2 / 3 / \mathrm{C} 4$ according to the CEAP classification (detected by systematic compression ultrasound and hemodynamic venous mapping). We randomized our study population Groups 2 in three Subgroup, admit to hospital, to receive : A) 33 pts. fondaparinux sodium, 2,5 mg/0,5 ml, B) 45 pts. enoxaparin sodium $40 \mathrm{mg} / 0,4 \mathrm{ml}, \mathrm{C}) 111$ pts. receiving other therapy.

\section{Results}

We have observed a minor incidence of venous thrombo-embolism (DVT) in Group 1 (that receiving
Table 1

\begin{tabular}{|c|c|c|c|c|c|}
\hline & $\begin{array}{l}\text { N. } \\
\text { pts. }\end{array}$ & Aged & DVT & EP & $\overline{\mathrm{P}<}$ \\
\hline Group 1 (CHD) & 214 & $71+/ 12$ years & $5,14 \%$ (11case) & $\begin{array}{l}1 \\
\text { case }\end{array}$ & \\
\hline $\begin{array}{l}\text { Group2 (CHD/ } \\
\text { IVC) }\end{array}$ & 187 & $\begin{array}{l}76+/-9 \\
\text { years }\end{array}$ & $8,5 \%$ (16 case) & $\begin{array}{l}1 \\
\text { case }\end{array}$ & 0,01 \\
\hline Subgroup A & 33 & $\begin{array}{l}72+/-4 \\
\text { years }\end{array}$ & $3 \%$ (1 case) & & \\
\hline Subgroup B & 45 & $\begin{array}{l}74+/-6 \\
\text { years }\end{array}$ & $2,2 \%$ (1 case) & & \\
\hline Subgroup C & 111 & $\begin{array}{l}75+/-9 \\
\text { years }\end{array}$ & $\begin{array}{l}12,6 \% \text { (14 } \\
\text { case) }\end{array}$ & $\begin{array}{l}1 \\
\text { case }\end{array}$ & 0,01 \\
\hline
\end{tabular}

for $45 \%$ LMWH and the remaining other) respectively the total Group two, as shown in Table 1, with a significant increase in thrombo-embolic risk, especially in the Subgroup C (absence LMW).

\section{Conclusions}

IVC is a disease of great social impact, certainly underestimated by the medical profession itself, also to its consequences. Therefore, we believe that in agreement with the major trials (Medenox, ecc.) IVC is a disease that strengthens the trombo-embolic risk comorbidity in CHD.

Published: 19 May 2010

doi:10.1186/1471-2318-10-S1-A52

Cite this article as: Ciciarello et al:: Chronic venous insufficiency

strengthens the thrombo-embolic risk in congestive heart failure in elderly patients. BMC Geriatrics 2010 10(Suppl 1):A52.

Cardiovascular Department, Sapienza University of Rome, Italy 